\title{
Tissue Banking in a Regulated Environment - Does This Help the Patient?
}

\section{Part 2 - Patient Views and Expectations (Including the EUROPA DONNA Forum UK Position)}

\author{
Bettina Borisch \\ Institute of Social and Preventive Medicine, University of Geneva, Geneva, Switzerland
}

\section{Key Words}

Empowerment $\cdot$ Tissue banking $\cdot$ Clinical research •

Consent $\cdot$ Regulatory developments

\begin{abstract}
Several scandals related to tissue collection have questioned the position of patients regarding tissue banking. The Human Tissue Act in the UK is a legal framework for tissue banking that has been evaluated by the Europa Donna Forum UK, an advocacy organisation for breast cancer. Patients are well aware of the importance of clinical research and want to see it strengthened. They envisage several modalities for tissue banking. One modality is the 'patient-driven' bank where some of the individual rights are transferred to the community, research done with the tissues is partly controlled by the patients, and information regarding the results is obtained back. However, for all models proposed, the point of prime importance for patients is the issue of consent. Copyright $\odot 2007$ S. Karger AG, Basel
\end{abstract}

\section{Introduction}

It is nowadays politically desirable to involve the patient or to request the so-called 'patient's view' before taking any health decision. In the case of tissue usage, the view of the person from whom the tissues was removed on what would be done with those tissues is even more complicated than just a 'view'. Tissues, cells and bodily fluids are intimately linked to the person's ethics, religion or superstitions. Several studies have explored the cultural, moral and social context of organ donation behaviour.

The role of cultural attitudes in organ donation has been addressed in Native Americans and other subgroups in the US population [1] as well as in the three language groups of Switzerland [2]. We should consider that tissue banking has been very close to organ donation in the public discussion and that the results obtained in studies of organ donation may be indicative of attitudes in tissue banking. Other points that shall influence lay public are the attitudes towards death and the dead body. Discussing tissues and organs involves the notion of disease and death. According to a Swedish survey, $65-75 \%$ of people feel some discomfort at the thought of organ donation and autopsy. Women are more sensitive toward operations on the dead body than men [3].

Prof. Bettina Borisch, MD, FRCPath

Institute of Social and Preventive Medicine, University of Geneva

CMU, 1, rue Michel Servet, CH-1211 Geneva 4 (Switzerland)

Tel. +41 2237959 54, Fax +412237959 12

E-Mail bettina.borisch@medecine.unige.ch 
It has to be kept in mind that the majority of persons concerned by providing tissues, who will be asked for consent, are usually suffering from a severe illness [4]. This particular situation differs from the general setting that prevails when a survey on a random sample of individuals is carried out. Patients concerned may have different attitudes as a result of a more chronic or a fulminating disease course or other characteristics of the disease. Consequently, the inclusion of different patient organisations and patient groups in the process of building guidelines for future usage of tissues is important. The consultations prior to establishing rules and guidelines, e.g. Human Tissue Act in England and in Scotland, will be the baseline for their acceptability. The consultation process may be a different one in every country and may relate to the cultural background and local possibilities. As seen in the first part of this article, people are open to questions of tissue collections and their usage 'if only they had been asked about beforehand'.

\section{Knowledge about Tissue Collections}

In the general public and even in the general medical public, the existence of tissue collections was not well known prior to the 'scandals' described in the first part of this article. These scandals arose mainly in departments of pathology, which have a long standing tradition in collecting tissue samples that are the leftovers of diagnostic tissue samples. As already mentioned in the first part of this article, the procedures in use were considered acceptable by most of the pathologists [5]. However, they were largely unknown in the general medical community and truly not in the lay public. While the knowledge about tissue collections was not well distributed, representations of such collections were present in the public.

Routine collections in the departments of pathology are not visible and even in large teaching hospitals, the departments of pathology are in the most remote places of the buildings so that patients have difficulties in visualizing a tissue bank or developing an image of what tissue banking means. As nobody knows what tissue banking or tissue collections really are, those words are likely to recall representations everybody unconsciously carries. Where did those representations originate?

The representations linked to parts of the human body go far beyond medicine: the 'knowledge' about tissues and their usage is influenced by arts and letters more than by the biomedical world. The terms such as collection or 'bank' do refer to other non-medical knowledge of property and profit. The feeling of being dispossessed by an authority outside one's own will is strong. These authorities could be medicine, up to now a strong and paternalistic authority, and the economic world - both forces that are not controlled by the patient. For several reasons, science and technology are under increasing public scrutiny. This also influences the attitudes and concepts around tissue banking. And even in a thriving economy, policymakers are keeping a closer eye on how research and development funds are spent. All these factors influence people's attitudes towards tissue banking and retaining organs. The way patients look at the problem will be shown by the example of the Europa Donna Forum United Kingdom (ED Forum UK), an organisation that has been involved relatively early in an environment that has decided on regulations in the form of the Human Tissue Act (HTA). ED Forum UK was probably among the first patient organisations in Europe to critically evaluate the draft of a legal framework for tissue banking.

\section{Ways Out - Strategies Proposed by Patients}

The ED Forum UK became involved when the HTA was reviewed and was a working party that met with a representative of the Ministry of Health who welcomed the initiative of ED UK. The main concern from the patient's point of view at that time was the lack of information and ensuing mystery around tissue banking and donation. Otherwise, patients usually responded positively after a clear explanation that was given from person to person. As had been clearly stated after the 'scandals' (see the study by Clark in this issue), patients were shocked by the fact that tissues and organs had been retained without their knowledge and consent. To overcome this deadlock, practical suggestions were made and a national information campaign was launched by ED UK on tissue banking to explain the procedure, the practices, the 'consent' and the implication of the patient. Other ways of broadening the dialogue are envisaged. There are possibilities of having open days at pathology departments. This has been shown to be beneficial in the understanding and attitudes towards tissue banking. Information would also be beneficial to the general medical public that could serve as a multiplicator of the information to both patients and the general public. The Royal College of Pathologists (www. rcpath.org) has made efforts to establish this communication and to foster the implication of pathologists in the discussions around tissue banking. Still very little re- 
search exists regarding the patient views; these studies mainly concern small subgroups of patients [6].

During the consultation process, patients and their advocates underlined the importance of clinical research. They feel that clinical research is still the bottleneck in European research strategies and want to see it strengthened. Tissue banks and collections are one means of improving clinical and translational research. 'There is already enough basic research at out there' according to Cathy Radcliffe [7]. Other patient groups have already underlined the importance of clinical research (see www. eu-patient.eu) and the extension of consultations about tissue collections will hopefully lead to a discussion about clinical research in general. There is a strong will to support clinical research, provided it is conducted according to guidelines that include an important degree of transparency. In general, patients are in favour of well-conducted research and are willing to contribute. ED - the European Breast Cancer Coalition represents the umbrella organisation of the national forums of ED which promotes awareness about clinical trials and tries to give in-depth information to women (www.cancerworld.org). A first example (supported by ED - the European Breast Cancer Coalition) of a clinical trial including an important translational research component using patient tissues is the MINDACT trial. In this prospective, phase III study, risk assessment using a gene expression signature is compared with risk assessment by common clinicalpathological criteria in selecting patients for adjuvant chemotherapy in node-negative breast cancer.

From the patients' point of view, at least three modalities of tissue banking can be recognized: (i) the tissue banks run with public funds and often linked to an academic institution or research facility, (ii) the tissue banks managed by patients but still run with public funds (e.g. Mary Ellen's Tissue Bank) and (iii) the patient-owned and patient-managed tissue bank. Around Europe, there are several examples of patient-owned or patient-organized tissue banks. In Germany, the breast cancer group 'Mamazone' organized a Patients' Tumorbank of Hope (PATH) as a joint venture of patients, physicians, researchers and the pharmaceutical industry (http://www.stiftungpath. org). The main difference among these models is the way in which the patient (or a group of patients, a community) influences the collection and its usage. Several of the more 'patient-driven' tissue banks were started by breast cancer activists. The breast cancer movement originated in part from the feminist movement and inherited some of the feminist theories. Practically, the group (in this case: the patients) transfers some of its individual rights

Tissue Banking: Patient Views and Expectations to the community for the sake of reaching the common goal (i.e. to promote knowledge about breast cancer). They also control the research done using the tissue bank and obtain information back as to the results of such research.

The other point of prime importance to patients is consent. The main issue in the consultations following the scandals in Bristol and Liverpool was consent: 'The fundamental principle that underpins the Act is consent. Consent is such a simple word that means so much, especially to the bereaved.' (Michaela Willis of the National Bereavement partnership and Human Tissue Authority member; www.hta.gov.uk ). The HTA is considered as an important step to regulate the consent. The ED Forum UK feels that regulation brought in by the HTA provides a transparent legal framework within which activity takes place. Still, the issue of consent in the context of tissue banking needs to be worked on. For instance, how to define the consent in case of a severe illness and how to define the possibilities of withdrawal of consent? Patients may be willing to have their tissues used for research but not for a commercial use. Where to draw the line? Many of the public institutions depend more and more on external funds for research; research can be done in the public and the private sector; industry has a major interest in procuring tissue collections with patient data; some industries sell tissue collections or already worked-upon tissue collections such as tissue micro-arrays; several open questions that will have to be answered in the near future. It may well be difficult for the patients to see further diversity emerge such as what is already the case for the HTA England and the HTA Scotland (see above). What will be the situation if patients will have to ask systematically what regulation applies to their tissues, as for instance in the context of an international study? What will be the attitude of local regulating bodies? As a first piece of evidence: the above-mentioned MINDACT trial involves numerous research centers around Europe, thus trying to gather tissues from different origins. Sweden did not accept to export tissues for this study. What will be the prevailing decision in such a case: is it the patient's will? Is it the general decision taken beforehand? There are important questions to be answered, and patient groups such as the ED Forum UK are willing to collaborate to find solutions.

The consent and regulatory developments in the UK are in a certain way a first step that is felt useful by the patients. At the same time, this work has opened up more questions and parts that need either discussion and/or regulations. The regulations such as HTA may some- 
times go as far as to be unacceptable on a European level. One important issue raised by ED is the European exchange of ideas and regulations, but also the avoidance of discriminatory differences among European Union member states.

\section{Impact on the Regulated Environment}

The UK is now one of the first countries in Europe providing a regulation that needs to show its practicability and acceptability in the long run. Patients feel that the HTA has brought transparency and a framework allowing further developments. Nevertheless, they underlined that there is a need for information that is not yet fulfilled. It is a very important question as to who should do this important information work and what kind of resources will be allocated to this work of communication among very different interest groups.

Apart from this work of information, other fields need to be worked upon. The definition of consent in the context of tissue donation is not yet clearly defined and will need a collaborative effort on the part of lawyers, doctors and patients to better define the 'consent' in this special setting. One indirect proof of the difficulties is shown by the different terminologies used in the HTAs of England and Scotland, where Scotland says 'authorisation' and England 'consent'. Is there place for creating different levels of consent? What about patients unable to decide on their own (e.g. infants and coma patients)? It is challenging to include those who work with the tissues and bring them in contact with those who will donate tissues for their research. Very little effort has been put on this aspect so far. However, given the fact that the different 'worlds' tend to converge via the communication media, this is another task to be taken up.

In other European countries, work on the problem of tissue banking is going on in almost every country; the impact of patients varies from country to country. The topic is very technical and it is probably one of the greatest challenges to communicate correctly and enable patients to state their positions. Some argue that research has become more complicated than years ago; the possibilities for researchers to involve their 'study subjects' directly and for patients to influence research, have never held a greater promise.

\section{References}

1 Pentz RD, Billot L, Wendler D: Research on stored biological samples: views of African American and White American cancer patients. Am J Med Genet A 2006;140:733739.

$\checkmark 2$ Schulz P, Nakamoto K, Brinberg D, Haes J: More than nation and knowledge: cultural micro-diversity and organ donation in Switzerland. Patient Educ Couns 2006;64:294302.

3 Sanner M: A comparison of public attitudes toward autopsy, organ donation, and anatomic dissection. A Swedish survey. JAMA 1994;271:284-288.
4 Lipworth W, Ankeny R, Kerridge I: Consent in crisis: the need to reconceptualize consent to tissue banking research. Intern Med J 2006;36:124-128.

5 Ashcroft R: The ethics of reusing archived tissue for research. Neuropathol Appl Neurobiol 2000;26:408-411.

6 Kaphingst KA, Janoff JM, Harris LN, Emmons KM: Views of female breast cancer patients who donated biologic samples regarding storage and use of samples for genetic research. Clin Genet 2006;69:393-398.

7 Neroth P: EU plans to boost research. Lancet 2005;365:1455-1456. 